\title{
Интегральные микросхемы считывания для ИК фотоприемников на основе твердых растворов теллуридов кадмия-ртути
}

В.М. Базовкин ${ }^{1)}$, С.А. Дворецкий ${ }^{1)}$, А.В. Зверев ${ }^{1)}$, А.П. Ковчавцев ${ }^{1)}$, Ю.С. Макаров ${ }^{1,2)}$, Г.Ю. Сидоров ${ }^{1)}$, А.В. Глухов ${ }^{2)}$, И.А. Смирнов ${ }^{2)}$, Д.В. Фромичев ${ }^{2)}$

${ }^{1}$ ИФП СО РАН им. А.В. Ржанова, Новосибирск, 630090, пр. ак. Лаврентьева, 13

${ }^{2} A O$ «НПП «Восток», Новосибирск, 630049, ул. Дуси Ковальчук, 276

тел: +7-923-134-6760, эл. почта: makarov@isp.nsc.ru

DOI 10.34077/RCSP2019-93

Фотоприемные устройства (ФПУ) на основе твердых растворов $\mathrm{HgCdTe}($ КРТ) представляют собой гибридную сборку матрицы фоточувствительных элементов (ФЧЭ) и кремниевой интегральной микросхемы считывания сигналов (ИМСС). ИМСС регистрирует фототоки со всех элементов матрицы ФЧЭ и затем последовательно выводит полученную информацию для построения изображения и его обработки внешним оборудованием. В настоящее время ключевые параметры ФПУ в значительной степени определяются характеристиками используемых ИМСС.

В средневолновом (3-5 мкм, СВИК) и длинноволновом (8-12 мкм, ДВИК) ИК-диапазонах величина фонового излучения обычно весьма велика, при этом уровень полезного сигнала, как правило, существенно ниже фона. Возможность выделения полезного сигнала на уровне фона ограничена такой характеристикой входной ячейки ИМСС, как зарядовая емкость. Из-за малой зарядовой емкости за полное время кадра накапливается лишь незначительная часть заряда, генерируемого падающим на ФЧЭ излучением. В результате не удается приблизиться к теоретически предельному значению температурного разрешения. В коротковолновом ИК-диапазоне (1-3 мкм, КВИК) величина потока обычно значительно ниже, чем в СВИК и, особенно, ДВИК диапазонах. Характеристики ФПУ в данном случае лимитированы собственными шумами ФЧЭ и ИМСС. Необходимость регистрации слабых потоков излучения требует интеграции емкостного трансимпедансного усилителя непосредственно во входную ячейку ИМСС.

ИМСС с входной схемой прямой инжекции

ИМСС формата $384 \times 288$ с шагом 25 мкм была разработана и изготовлена в режиме «foundry» по технологии ХC06 фирмы XFab. Основные характеристики: зарядовая емкость в режиме считывания во время интегрирования (IWR) $20 \mathrm{Me}$; частота вывода информации 20 МГц; кадровая частота 680 Гц; потребляемая мощность не более 100 мВт. Подробное описание конструкции и функциональных возможностей представлено в [1].

Ведется разработка ИМСС формата 640×512 с шагом 15 мкм по технологии XС018 фирмы XFab. Ожидаемые характеристики: размах выходного напряжения $1,5 \mathrm{~B}$; зарядовая емкость входной ячейки в режиме считывания после интегрирования (ITR) $12 \mathrm{Me}^{-}$, в режиме IWR $9 \mathrm{Me}^{-}$; частота вывода информации $20 \mathrm{MГц,} \mathrm{кадровая} \mathrm{частота} 240$ Гц; потребляемая мощность не более 60 мВт. В проект заложены следующие функциональные возможности: управление с помощью последовательного интерфейса; возможность выбора накопительной емкости между двумя фиксированными значениями; режим «окна»; встроенные ЦАПы для формирования управляющих напряжений; возможность подстройки коэффициентов преобразования аналоговых узлов.

ИМСС с входной схемой на базе емкостного трансимпедансного усилителя

ИМСС формата 2000×2000 работает в режиме моментального снимка («snapshot»), при этом считывание осуществляется после интегрирования. Размах выходного напряжения 2 В, зарядовая емкость 1,9 Mе', частота вывода информации не менее 8 МГц. ИМСС имеет восемь сигнальных выходов, потребляемая мощность не превышает 450 мВт. Собственный шум считывания менее $300 \mathrm{e}$. Дополнительно реализована функция «антиблюминга», предотвращающая переполнение входной ячейки и последующее растекание заряда. На базе данной ИМСС впервые в России изготовлены гибридные КРТ ФПУ с форматом, превышающим один мегапиксель.

ИМСС формата $1536 \times 1536$ предназначена для использования в составе стыкуемых гибридных КВИК фотоприемных модулей (ФМ). ФМ стыкуются по двум сторонам, образуя мозаичное ФПУ формата $3072 \times 3072$. ИМСС также работает в ITR режиме. Помимо функции «антиблюминга» имеется возможность выбора величины накопительной емкости между двумя фиксированными значениями. Размах выходного напряжения 2,5 В, зарядовая емкость входной ячейки переключается между $450 \mathrm{ke}^{-}$и $2,2 \mathrm{Me}^{-}$, частота вывода информации не менее 8 МГц. ИМСС имеет четыре сигнальных выхода, потребляемая мощность не превышает 400 мВт.

\section{Лuтература}

[1] A.V. Zverev, Yu. S. Makarov, E. A. Mikhantiev, I. V. Sabinina, G. Yu. Sidorov, and S. A. Dvoretskiy, Journal of Physics: Conference Series 643, 012055 (2015). 